\title{
A LONGITUDINAL STUDY OF THE INDICATORS AND FACTORS FOR SUCCESSFUL SIX SIGMA DEPLOYMENT IN THE SOUTH AFRICAN MINING INDUSTRY
}

\author{
A. L. Keeley ${ }^{1}$, C.C. van Waveren ${ }^{2 *} \&$ K.-Y. Chan $^{3}$ \\ ${ }^{1,2,3}$ Graduate School of Technology Management \\ University of Pretoria, South Africa \\ 1alanleigh@mweb.co.za; ${ }^{2}$ corro@up.ac.za; ${ }^{3}$ alice.chan@up.ac.za
}

\begin{abstract}
The Six Sigma deployment methodology is known for its results in operational excellence associated with improved business practices. Organisations worldwide have shown significantly reduced costs and increased profits when successfully deploying Six Sigma. This paper reports a longitudinal study of a set of indicators and success factors for Six Sigma deployment, using Lonmin PLC, a mining company in South Africa, as a case. The results suggest a shift of indicators from heartfelt personal involvement in 2006 to a mechanistic performance-based culture in 2010. Practical recommendations are made regarding the nine success factor components to be included during Six Sigma deployment.
\end{abstract}

\section{OPSOMMING}

Die ontplooiing van die sogenaamde "Six Sigma"-metode het 'n bydrae gemaak tot bedryfsuitnemendheid deur verbeterde sakepraktyke aan te moedig in die bereiking van laer koste en verbeterde wins. Verslag word gedoen oor ' $n$ versameling van sake-indikatore en suksesfaktore in ' $n$ gevallestudie van ' $n$ Suid-Afrikaanse mynmaatskappy. Voorstelle word gemaak oor die aanwending van nege suksesfaktore wanneer die "Six Sigma"-metode gebruik word.

\footnotetext{
${ }^{1}$ The author was enrolled for an M Eng (Engineering Management) degree in the Graduate School of Technology Management, University of Pretoria.

* Corresponding author
} 


\section{INTRODUCTION}

Since the late 1800s the South African mining industry has been the cornerstone of the development of the South African economy [1]. With the discovery of gold (from 1870 to 1886) on the Witwatersrand and diamonds (1867) in Kimberley, mining became the hub around which the South African economy was built; and historically this has been the single most important factor in the economic growth of the country. Mining employs hundreds of thousands of people, while the secondary industries that have been developed to supply and service the industry employ many more. The 2007/ 2008 global economic crisis has had an impact on the profitability of the South African mining industry. A significant reduction in productivity, efficiency, and effectiveness has also been experienced from factors such as higher production costs, the restructuring of operations, and the decline in the availability of credit or liquidity [2]. Coupled with this has been pressure from the South African government - and specifically the Department of Minerals and Energy (DME) - to transform the industry so that, through black economic participation, there is a greater representation of historically disadvantaged South Africans (HDSA) at all levels of management [3]. These requirements are defined in the Broad-Based Socio-Economic Empowerment Charter for the South African mining industry [4].

The objectives of this charter [4] are to:

- promote equitable access to the nation's mineral resources for all the people of South Africa;

- substantially and meaningfully expand opportunities for HDSA, including women, to enter the mining and minerals industry and to benefit from the exploitation of the nation's mineral resources;

- use the existing skills base for the empowerment of HDSA;

- expand the skills base of HDSA in order to serve the community;

- promote employment and advance the social and economic welfare of mining communities and the maj or labour-sending areas; and

- promote beneficiation of South Africa's mineral commodities.

In 2007 the mining and quarrying sector contributed R135.5 billion or 7.7 per cent to South Africa's gross domestic product (GDP). This was 13.4 per cent higher than in 2006. South Africa's total primary mineral sales contributed R223.9 billion to the country's GDP, which was 14.5 per cent higher than in 2006. The mining sector employed 2.9 per cent of the country's economically-active population in 2006. This number increased by 8.6 per cent to 495, 474 in 2007 [5]. The drive to extract the maximum value from the country's mineral resources, as required by the Minerals and Petroleum Resources Development Act (MPRDA) and the Mining Charter, appears to be gaining momentum. This is evident in the development of a beneficiation policy and strategy, which seeks to increase the level of local beneficiation, promote job creation, and increase the industry's contribution to GDP. In 2007 the processed minerals subsector generated in excess of R54 billion in sales revenue - 26.3 per cent higher than in 2006 [6]. The mining and minerals sector contributes significantly to attaining the target of the Accelerated and Shared Growth Initiative for South Africa (Asgi-SA) to achieve accelerated economic growth, and to halve unemployment and poverty by 2014. To this end, the country continues to strive for the development of policies that create an attractive investment climate, as shown by the amendment of the MPRDA [7], which is in the final stages of consideration by the country's lawmakers.

However, the rapidly-deteriorating world economic outlook - brought about by the current international subprime financial crisis - resulted in the commodity process being propelled upwards. For example, the Economist's metals index rose by 384 between October 2001 and mid-2007. This build-up in stockpiles of various minerals indicates that the financial crisis has affected the global demand for minerals, and undermines the commodity cycle [2]. South Africa, which is dependent on foreign trade, is therefore unlikely to remain isolated from the global financial crisis-induced economic slowdown. The impacts of the global economic crisis on the South African mining sector can be seen in the job losses 
resulting from the restructuring of operations. Lower revenues and higher production costs caused some mines or shafts to close because their costs of production exceed their revenues [2]. Of equal concern is the potential impact of reduced demand on the prices of these commodities [8]. A well-co-ordinated and focused approach by all mining industry stakeholders is required to mitigate the impact of the financial crisis.

Due to the credit crunch and fierce competition for capital, investors have become extremely selective, and there is a need for transformation in line with the Mining Charter in the South African mining industry. Companies that can show sustainable operational and capital growth, and that can provide a sustainable stream of dividend flows to their shareholders, will be successful in the long run and will trade at a premium to their competitors on the global stock exchanges. An integrated methodology that can facilitate a sustainable transformation of employee motivation, that can produce high quality innovative products at lower cost while maintaining good customer relationships, and that makes use of a systems-based approach could solve the many challenges that corporations operating in the South African mining space face.

Many transformation and change initiative projects that aim to achieve the representation required by the Mining Charter and improve worker and organisational productivity have been launched within the various mining houses. For example, prior to 2008, Lonmin PLC (one of South Africa's largest mining houses) was structured as an entity with accountability for quality and improvements defined under a Centre of Excellence (COE) model. The reason for this approach was the belief that significant benefits could accrue from providing the Six Sigma initiative with its own leadership and resources. Projects would be based on business requirements, but dedicated Six Sigma Black Belts would be assigned to each project and incentivised to manage the projects through the DMAIC (Define, Measure, Analyse, Improve \& Control) process, and to embed the outcomes on a sustainable basis within the business. This ensured that Black Belts were highly motivated and had a direct line to decision makers and resources to ensure that their projects were successfully concluded. This is evident in the results achieved during the initial implementation from 2005 to 2007. Feedback was rapid, support was immediately available, and there was active planning and participation from leadership within the COE. Six Sigma Black Belts had a unique identity and were considered the cream of the crop. The economic downturn in 2008 forced Lonmin to review its operating model, and during a process of downsizing and reorganisation the decision was taken to close the Six Sigma COE and reintegrate the initiative as a line function within the business. This had a number of unintended consequences. Six Sigma Black Belts were now forced to compete with a number of potentially conflicting initiatives. Cost-saving drives resulted in fewer resources being available, and the Six Sigma focused reward systems were discontinued. The identity that had been created, which saw Six Sigma Black Belts as the future leaders of the business, became tarnished, and motivation levels were eroded. The approach appeared to change from a leadership-initiated approach to a more management-focused one. This is evident in the move from continuous engagement to monthly reviews, the need for initiative alignment as opposed to a single point of focus, and the continual tension created by the competition for scarce resources. There is therefore much to learn from the successes and failures of the two approaches. Lonmin's proposed transformation initiative in 2008 can be compiled from three complementary approaches which, when integrated into a single transformation intervention, would significantly enhance the chances of a successful outcome. These approaches (or methodologies) are:

1. Six Sigma continuous improvement methodology

2. Kotter's theory on change management

3. Kaplan and Norton's balanced score card and strategy map theory.

Lonmin PLC integrated these three approaches and developed a seven-step deployment process for the successful implementation of Six Sigma. The objective of this paper is therefore to review the Six Sigma deployment undertaken by Lonmin PLC in 2006 (when it was initiated with a centralised 'centre of excellence' structure), and in 2010 (after the 
structure had been changed in 2008 to a structure where the core competencies were reintegrated back into the line functions of the organisation), and answer the following two main research questions:

1. Which success model did Lonmin PLC follow in 2006 and in 2010 ?

2. What is the level of Six Sigma deployment in Lonmin PLC in 2010 compared with its initial deployment level in 2006?

In order to explore the success model, two aspects are considered. The indicators that measure the level of successful deployment of Six Sigma will be investigated; and several success factors that may contribute to the level of successful deployment of Six Sigma will be identified. These success factors will form the basis of the Success Factor Model of Six Sigma deployment. Followed by the main research question, two sub-questions are formulated as follows:

1. What indicators determine the level of successful deployment of Six Sigma?

2. What are the success factors of a Six Sigma deployment?

The remainder of this paper is structured as follows. Section 2 provides a brief review of the three methodologies that were used by the Lonmin executive team to identify the success factors of a Six Sigma deployment. Moreover, in Section 2 a seven-step deployment process, which was developed from the three methodologies by the Lonmin executive team, is discussed as a framework to identify indicators that would determine the level of success associated with a Six Sigma deployment initiative. Section 3 describes the research methodology and the data analysis techniques that are applied in this study. Section 4 describes the empirical results from the paired sample t-test and factor analysis. The discussion in this section includes the differences between the results in 2006 and in 2010. Section 5 provides some concluding remarks.

\section{THEORETICAL FRAMEWORK}

This section reviews the three approaches that were integrated by the Lonmin executive team to develop a seven-step deployment process. Thirteen indicators were identified during this review process; and these are detailed in this section. The second part of this section reviews the success factor models in past Six Sigma literature. These models formed the basis for further identification of success factors during the brainstorming sections and semi-structured interviews in Lonmin. As a result of the brainstorming and interviews, 40 key success factors were identified that were required to ensure the success of Six Sigma deployment in Lonmin.

\subsection{Six Sigma methodology}

The Six Sigma process improvement methodology was developed by Bill Smith of the Motorola Corporation [9]. In 1981 the semiconductor industry was under severe strain, with the cost of manufacture exceeding the revenue generated from the sale of semiconductor chips. Interest rates were extremely high at 18 to 20 per cent, and the Motorola Corporation Semiconductor Division's financial statements indicated a company in serious financial difficulty. This led Smith and his colleagues at Motorola to start developing tools and methodologies aimed at improving product quality. Six Sigma today focuses on establishing world-class business performance benchmarks, and on providing an organisational structure and road map by which these can be realised [10]. This is mainly achieved on a project-by-project basis, using a workforce trained in performanceenhancement techniques with a receptive company culture and perpetuating infrastructure. Although particularly relevant to the enhancing of value of products and services from a customer perspective, Six Sigma is also directly applicable to improving the effectiveness and efficiency of all processes, tasks, and transactions within any organisation [11]. The Six Sigma methodology has been used successfully as a quality control methodology in many organisations, including Lean Manufacturing, Total Quality Management, and the International Organisation for Standardisation (ISO) quality system 
standards. The Six Sigma methodology has also been successfully applied as a continuous improvement methodology by applying a rigorous set of tools within a continuous improvement methodology called DMAIC (Define, Measure, Analyse, Improve \& Control). Six Sigma has its origin in the introduction of the normal distribution as defined by Carl Fredrick Gauss (1777-1855). Walter A. Shewhart (1891-1967) expanded this concept by introducing product variation from the mean value as a key control mechanism for quality control. In the early 1980s, engineers at Motorola decided that the traditional method of measuring defects relative to a scale of thousands did not provide sufficient granularity for effective quality management and variance control, and decided to increase the scale to defects per million opportunities (DPMO). Motorola developed the Six Sigma concept and the methodologies that support it, and registered the Six Sigma trademark as their own. Many companies around the world have successfully implemented the Six Sigma methodology, with most successes experienced in Northern America and to a lesser extent in Europe. Global corporations such as General Electric and Allied Signal have attributed billions of dollars of savings and productivity improvements to the methodology. An early USA convert to Six Sigma, Jack Welch (chief executive officer of General Electric), describes Six Sigma as "the most challenging and potentially rewarding initiative we have ever undertaken at General Electric" [12]. The Six Sigma methodology could potentially be a tool for improving organisational and employee productivity in the South African mining environment.

\subsection{Kotter's theory of change management}

Kotter [13] stated that "[b]y any objective measure, the amount of significant, often traumatic change in organizations has grown tremendously over the past two decades". Since the time this statement was made, the amount of change that has taken place within the South African context has created further stress within its social structures, and the impact on the business and mining community has been equally vast. The introduction of the South African Mining Charter, black economic empowerment (BEE), affirmative action legislation, and finally the 2007/2008 global economic crisis have placed enormous pressure on corporations operating within the South African mining industry. A structured and sustainable approach to change management is required if South African mining companies are to remain competitive and to survive in the long run.

Kotter [13] also states that "[t]o date, major change efforts have helped some organizations adapt significantly to shifting conditions, have improved the competitive standing of others, and have positioned a few for a far better future. But in too many situations the improvements have been disappointing and the carnage has been appalling, with wasted resources and burn-out, scared or frustrated employees".

Kotter [13] suggests that eight common errors are the source of the failure of transformation and change efforts. These errors are listed below:

- Allowing too much complacency

- Failing to create a sufficiently powerful guiding coalition

- Underestimating the power of vision

- Under-communicating the vision by a factor of 10 (or 100 or even 1,000 )

- Permitting obstacles to block the new vision

- Failing to create short term wins

- Declaring victory too soon

- Neglecting to anchor changes firmly in the corporate culture

Kotter states that "[n]one of these errors would be costly in a slower moving and less competitive world. Handling new initiatives quickly is not an essential component of success in relatively stable or cartel-like environments. The problem for us today is that stability is no longer the norm. And most experts agree that over the next few decades the business environment will become only more volatile" [13]. Kotter provides valuable insight into the process of Six Sigma deployment. At the systems level, Six Sigma is a well-defined methodology that uses statistical tools and project-based processes to improve product 
quality by reducing variance. Change management is an essential part of creating sustainable deployment. Integrating Kotter's theory into the Six Sigma deployment process would significantly improve the chances of a lasting transformation.

\subsection{Kaplan and Norton's balanced score card (BSC) and strategy map theory}

With the advent of the Internet, e-commerce, and social media such as Facebook and Twitter, customers have become increasingly demanding, and business has become increasingly competitive. The focus has thus moved from the traditional forms of competitive advantage such as technology leapfrogging, cost leadership, and economies of scale, to more intangible advantages such customer relationship, innovative and high quality products that are brought to market rapidly, and a highly motivated and skilled workforce who apply their knowledge and experience in delivering products and services to specifically targeted customer segments through the use of systems based on databases and information technology. This shift of focus implies that a new approach is required to position organisations in such a way that they are able to compete in a global real time market. Such organisations are called 'strategy focused organisations' [14].

Strategy focused organisations follow five management principles to become strategy focused. They [14]:

1. Translate strategy into operational terms

2. Align the organisation to the strategy

3. Make strategy everyone's everyday job

4. Make strategy a continual process

5. Mobilise change through executive leadership

According to Kaplan and Norton [15], a strategy map for a balanced scorecard makes an explicit strategy's hypothesis. Each measure of a balanced scorecard becomes embedded in a chain of cause-and-effect logic that connects the desired outcomes from the strategy with the drivers that will lead to the desired outcomes. While listing the objectives in the four perspectives, executives instinctively draw arrows to link the objectives. They can now articulate their strategy of how improving employee capabilities and skills in certain job positions, coupled with new technology, would enable a critical internal process to improve [14]. A common failure in organisations is the lack of connection between the outputs generated by internal processes and the needs and value proposition of the customer. Equally poorly addressed are innovation, employee skills development, and the role of information technology. Strategy maps address this shortcoming. This puts intangible assets in a framework where they can be managed effectively. Moreover, a strategy map provides a single-page view of how objectives in the four perspectives integrate and combine to describe the strategy [14]. Quality measurements play a vital role in strategy maps. They are essential to both customer and internal perspectives. "A well-functioning quality measurement program provides critical measurements to internal and customer objectives in most organisations' Strategy Maps" [14]. Strategy maps provide a unique opportunity to organisations that plan to implement, or have already implemented, a continuous improvement or quality management programme. This can be achieved in four ways:

1. The balanced scorecard (BSC) provides an explicit causal linkage through strategy maps and cascaded objectives. Through the process of determining and defining the organisational goals, targets, and initiatives, executives are able to create alignment in their approach, gain team commitment to the outcomes required, and provide clarity to themselves and ultimately the employees within the organisation about the road ahead. The chosen objectives must be customer-focused, and the quality management system must be focused around strategic objectives. Often quality management systems focus on short-term wins at the expense of long-term sustainable performance. This shortcoming must be eliminated if the quality system is to be successful.

2. The BSC establishes targets for breakthrough performance, not merely to match existing best practice. Optimising existing systems within the context of best practice is often 
not enough. Radical transformation might be the only way in which an organisation can guarantee its survival. Matching the benchmark set by competitor organisations implies that one's own organisation can never be the industry benchmark. Becoming the industry benchmark is the best way to guarantee sustainable performance. Set bold targets and stretch them, and align the organisation and its resources around achieving them.

3. The BSC often identifies entirely new processes that are critical for achieving strategic objectives. "Quality models strive to improve existing organisational processes, making them better, faster and cheaper" [14]. Often the only way forward is to develop or invent new processes that can provide a leapfrog advantage. Once these processes have been integrated into the business, the quality programme can be used to improve and optimise the new process.

4. The BSC sets strategic priorities for process enhancements. A gap analysis using benchmarking can be conducted to identify the key strategic processes that drive value creation within the organisation. This enables the organisation to assign scarce resources to those processes that are essential to the role, out of the organisational strategy. "A properly developed strategy map provides strategic focus to activity based management and quality management programmes. It embeds these improvement programmes within a strategic framework that provides clear line-of-sight impact from process improvements to important organisational outcomes" [14].

By integrating these three methodologies, the Lonmin executive team identified 40 factors that could lead to a successful Six Sigma deployment. Details of these factors are shown in Appendix 1. These factors will be tested in this research to formulate a success model for the South African mining industry.

\subsection{Seven-step deployment process}

The three methodologies were integrated by the Lonmin executive team into a deployment plan for the successful implementation of Six Sigma. A seven-step deployment process was then developed by the team, as shown in Figure 1. The process steps are described under the following subheadings:

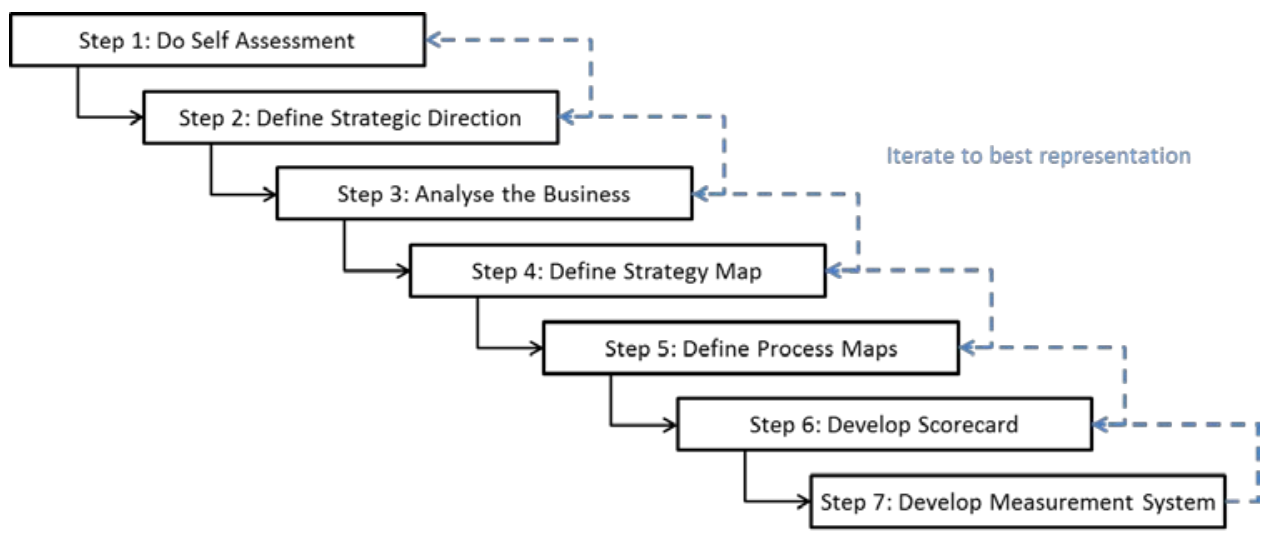

Figure 1: Seven-step deployment process

\subsubsection{Process step 1: Do self-assessment}

Lonmin embarked on a self-assessment test to establish a common understanding of its 'as was' state and to help it identify various opportunities for improvement. Use was made of a generic quality and self-assessment methodology, and the data gathered was supplemented by interviews with key organisational leaders. Once the assessment was completed the key findings were shared with all employees within the organisation to create a burning 
platform for organisational change. This was important for the success of the initiative, as it created the driving force that was required to sustain the organisation during periods of self-doubt and significant change.

\subsubsection{Process step 2: Define strategic direction}

On the completion of Step 1, Lonmin had a clear understanding of the issues and problems that it was facing. This allowed it to formulate a new strategic direction and strategic intent. The strategic formulation process shown in Figure 2 was followed. Once the strategy had been defined, a new set of goals and targets was formulated for the organisation.

\subsubsection{Process step 3: Analyse the business}

Once the strategy formulation process was completed, Lonmin made use of Kaplan and Norton's four perspective model [14] to analyse its business. A process model for the organisation was then created that provided the next building block for the development of the organisational strategy map. This model is defined in Figure 3 below.
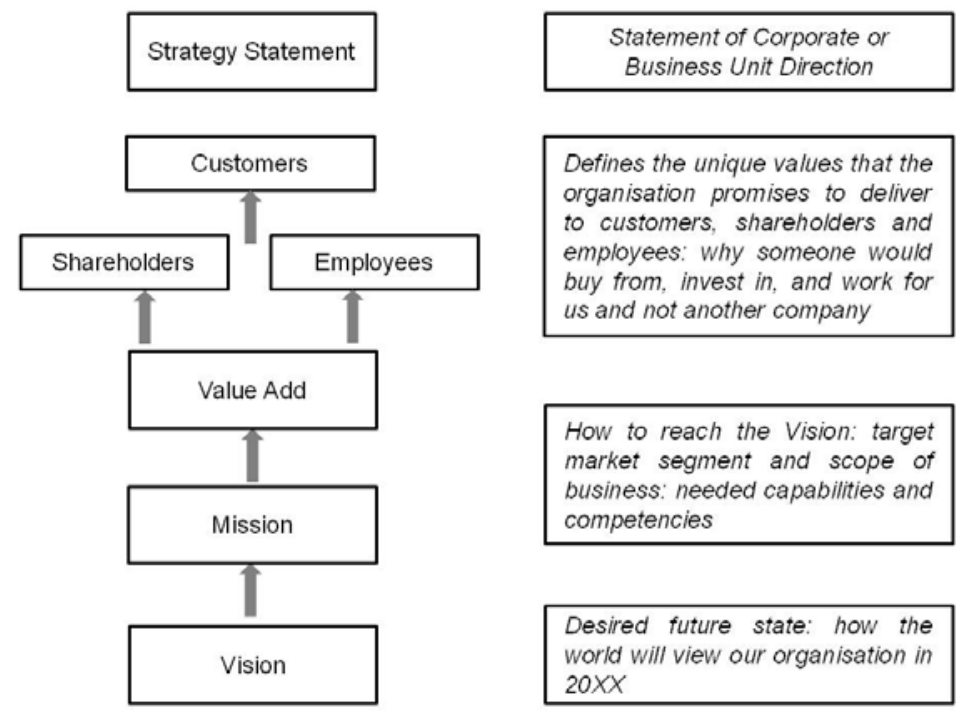

Figure 2: Strategy formulation process

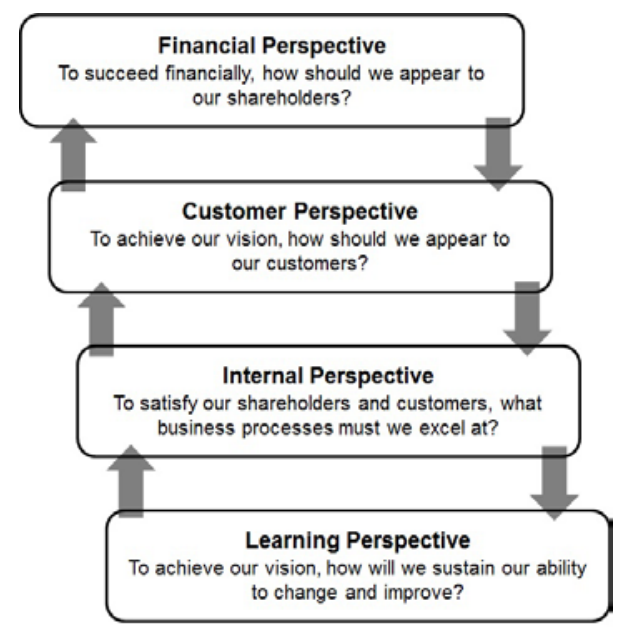

Figure 3: Kaplan and Norton's four perspectives [14] 


\subsubsection{Process step 4: Define a strategy map}

Based on the data gathered and the analysis conducted in Step 3, Lonmin was able to define a strategy map for the organisation, shown in Figure 4. A reassessment of the historical metrics had to be undertaken to ensure that the metrics were convertible into the Six Sigma methodology, and to ensure that the successful execution of the metrics would result in the achievement of the organisational strategy.

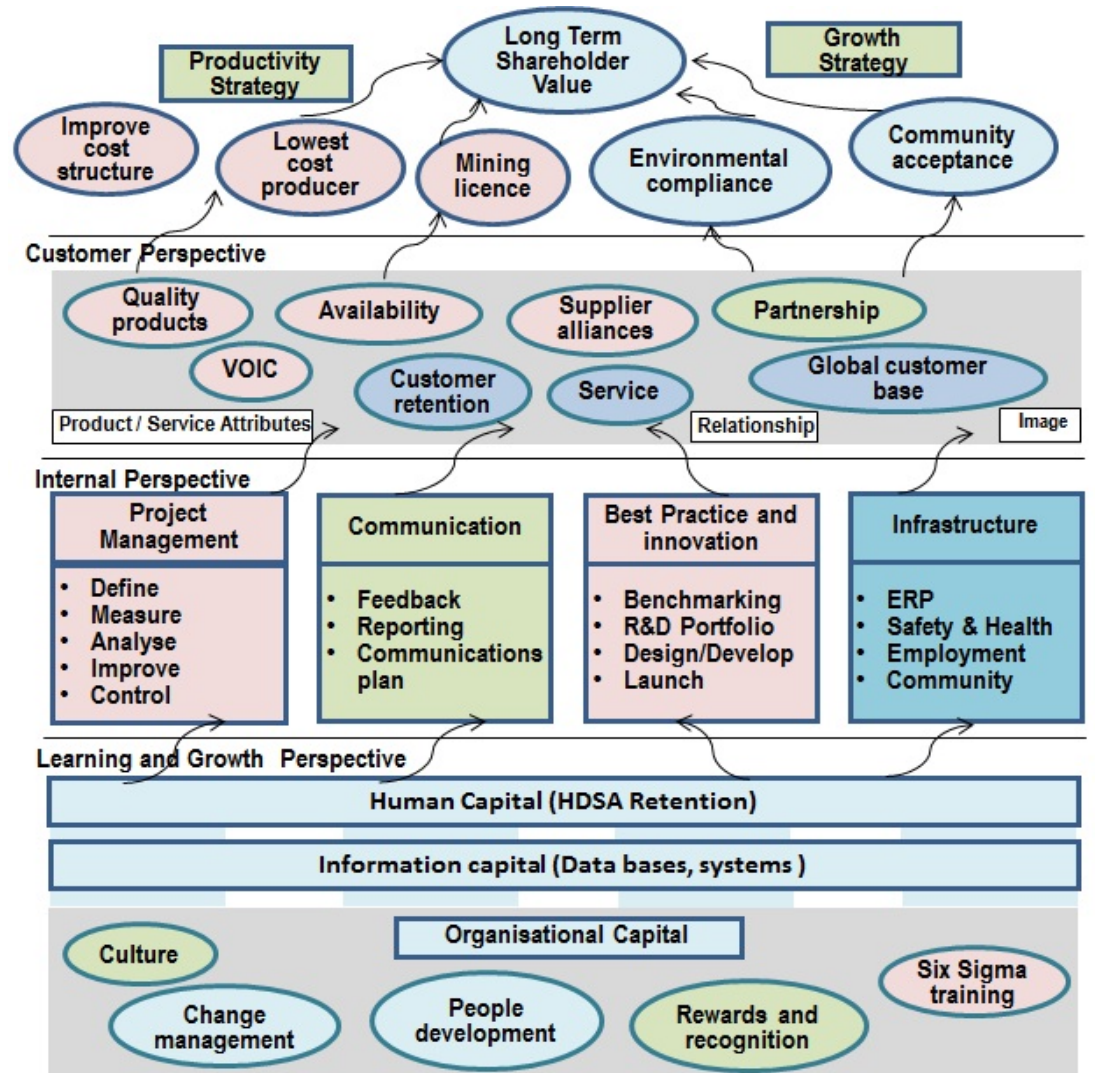

Figure 4: Lonmin's strategy map

\subsubsection{Process step 5: Define process maps}

The next part of the process required the development of high level process maps for the key core and support processes making use of the supplier, input, process, output and customer (SIPOC) methodology [16]. A generic high level process model for the mining industry is shown in Figure 5. Once the model was completed, key metrics were defined for each of the processes. These metrics were related to the voice of the customer (VOIC) feedback, and were converted to Six Sigma metrics such as defects per million opportunities (DPMO), Sigma level, or rolled throughput yield (RTY). A good mix of lead and lag metrics was defined to measure on-going performance.

\subsubsection{Process step 6: Develop a scorecard}

Use was then made of the Kaplan and Norton [17] balanced scorecard methodology as shown in Figure 6, to cascade the organisational score card to all levels within the organisation and to align the metrics at the departmental or sub-group level with those of the organisation. This ensured that the selected metrics were aligned at both a vertical and a horizontal level to ensure an integrated reward strategy that optimised the system or organisation in a holistic manner. 


\subsubsection{Process Step 7: Develop a measurement system}

The final step involved the gathering and analysis of data relative to the key metrics, identifying and analysing the gaps between the 'as was' state and the 'desired future state', and the formulation of projects to rectify the shortcomings. This approach integrated the concept of sustainable change and the balanced scorecard concepts into a single model for Six Sigma deployment.

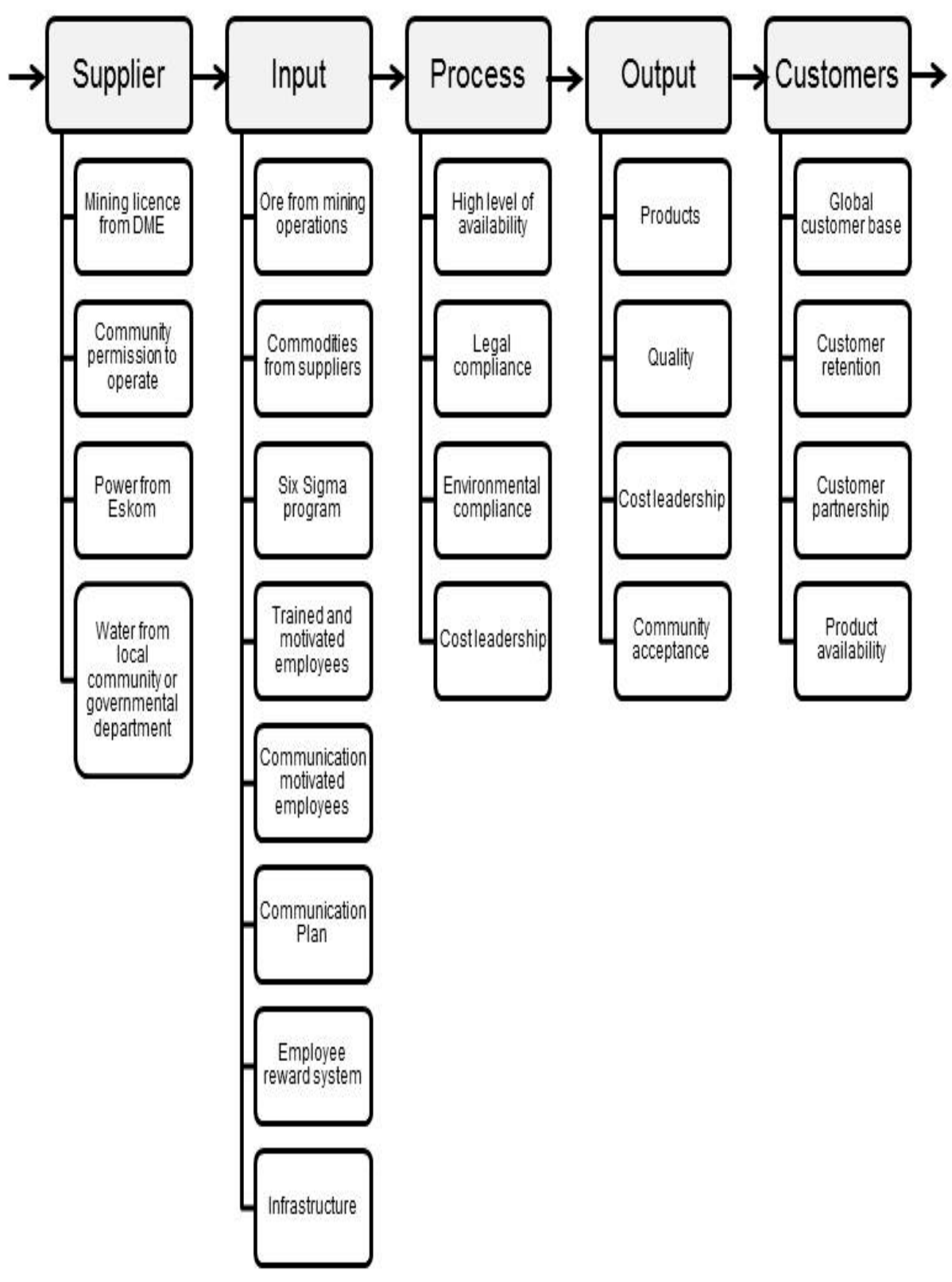

Figure 5: Generic process model for the mining industry 


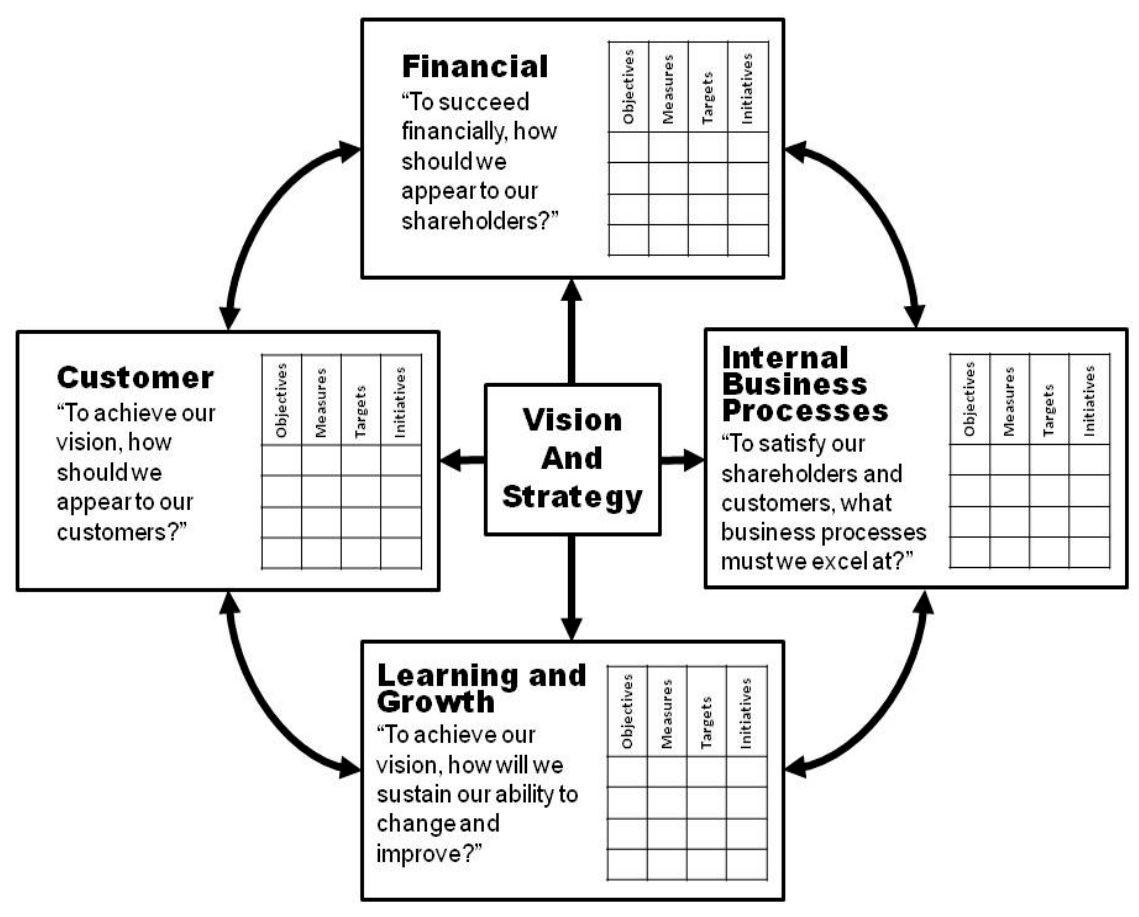

Figure 6: Balanced scorecard (adapted from [17])

\subsection{Indicators for Six Sigma deployment}

By using the seven-step process, Lonmin's execute team identified 13 key indicators for Six Sigma deployment. The 13 key Six Sigma deployment indicators are listed as follows:

1. A clearly defined Six Sigma deployment plan

2. Active participation in, and the commitment of the senior executives to, the Six Sigma deployment

3. Regular Six Sigma project reviews

4. Technical support from Six Sigma Master Black Belts and Black Belts

5. Full time Six Sigma Master Black Belts and Black Belts

6. Six Sigma training programmes for all employees

7. A plan to communicate the Six Sigma programme to the entire organisation

8. A Six Sigma project selection methodology

9. A system to track all Six Sigma projects

10. A Six Sigma incentive programme

11. A safe environment that allows employees to tell the truth regarding their respective areas of responsibility

12. A clear plan for dealing with internal and external suppliers

13. A Six Sigma programme that focuses on the needs of internal and external customers

This study will further explore the indicators identified by Lonmin's execute team.

\subsection{Literature survey on success factors for Six Sigma deployment}

Recent studies have reviewed the Six Sigma literature as an approach to identifying key factors for success during Six Sigma deployment. Antony and Banuelas [18] carried out an exploratory study and identified eleven critical success factors (CSFs) from the studies performed by authors such as Pande et al. [19], Henderson and Evans [20], and Eckes [21]. Their list includes the following factors: 
1. Management involvement and commitment

2. Cultural change

3. Organisation infrastructure

4. Training

5. Project management skills

6. Project prioritisation and selection, reviews, and tracking

7. Understanding the Six Sigma methodology, tools, and techniques

8. Linking Six Sigma to business strategy

9. Linking Six Sigma to the customer

10. Linking Six Sigma to human resources

11. Linking Six Sigma to suppliers

The study by Coronado and Antony [22] has a similar list of success factors to those in Antony and Banuelas' list [18], with the addition of 'Communication'.

In 2004, Antony extracted 40 variables or statements from the literature $[23,21,24$, $19,25,26]$ and grouped them under 13 critical success factors using the affinity diagram tool. This set of factors is similar to the previous set, but with slight modifications. Antony did a pilot survey in UK service organisations and reported the list of success factors in descending order:
1. Linking Six Sigma to business strategy
2. Customer focus
3. Project management skills
4. Executive leadership and senior management commitment
5. Organisational infrastructure
6. Project selection and prioritisation
7. Management of cultural change
8. Integration of Six Sigma with financial accountability
9. Understanding the DMAIC methodology
10. Training and education
11. Project tracking and reviews
12. Incentive programme
13. Company-wide commitment

Kwak and Anbari [27] proposed four key elements of successful Six Sigma applications based on the literature by Antony and Banuelas [18], Coronado and Antony [22], Johnson and Swisher [28], and Starbird [29]. These four key elements are:
1. Management involvement and organisational commitment
2. Project selection, management, and control skills
3. Encouraging and accepting cultural change
4. Continuous education and training

Ho et al. [30] did a survey study using questionnaires containing 70 items/ questions. The survey was done on 113 employees who attended Green Belt training at a company in Taiwan. The authors performed factor analysis on the 70 items/ questions and extracted five success factors:
1. Incentive/ reward system
2. Investment of essential resources
3. Business strategy based on customer demands
4. The use of data analysis with data that is easily obtainable
5. Top management's commitment and participation

In 2009, Coronel et al. [31] used the same set of questions as Ho et al. [30] and did a survey using a sample of ten local companies belonging to the export manufacturing sector in Spain. The factor analysis results show five latent variables or success factors as: 
1. Top management's commitment

2. Team work and cooperation

3. Six Sigma role structure

4. Mentoring

5. Execution and reward

A more recent study by Brun [32] made two small modifications to the list of Anthony and Banuelas [18]. They expanded 'training' to 'education and training', and 'organisational infrastructure' to 'organisational infrastructure and culture'. Brun [32] then did a statistical analysis of the frequency of the various success factors from a sample of 18 papers, and verified that these factors were indeed mentioned several times in the literature.

Sambhe [33] identified fifteen critical success factors for Six Sigma implementation, and ranked them based on the survey results he obtained from medium-scale automotive industries in India. These are (in descending order):

1. Top management leadership and commitment

2. Team selection for Six Sigma project

3. A well-developed strategic planning system

4. Employee training and education on Six Sigma methodology, and utilisation of quality tools

5. Effective communication on Six Sigma programme

6. Project prioritisation and selection

7. Linking Six Sigma to business strategy

8. Organisational infrastructure

9. A well-implemented customer management system

10. Culture of collaboration and cooperation

11. Project management skills

12. Empowerment and authority at all levels

13. Linking Six Sigma to suppliers

14. Linking Six Sigma to business strategy

15. Role of information technology

Based on the combined success factors identified in this previous research, semi-structured interviews were undertaken with 14 Six Sigma Master Black Belts and Black Belts from Lonmin who were involved in the original deployment programme. They were requested to comment on the success of the Six Sigma deployment, and to identify factors applicable to Lonmin's context. As a result, 40 items/ factors were identified that relate to the success of Six Sigma deployment within the company. Details of these items/factors are shown in Appendix 1. These items will be tested in this research to formulate a success model that might represent the South African mining industry.

\section{RESEARCH METHODOLOGY}

\subsection{Sample and data collection}

\subsubsection{Semi-structured interviews}

Interviews were conducted with the Six Sigma Master Black Belts and Black Belts who were involved in the original deployment programme. A total of 14 candidates were interviewed, representing 25 per cent of the total number of Master Black Belts and Black Belts at Lonmin at the time of the study. Candidates were requested to comment on the success or failure of the Six Sigma deployment, and to identify key reasons for the success or failure of the deployment. They were also requested to contrast the original deployment with the post-reorganisation and restructuring period, and to provide an opinion on the differences between the two approaches - these being a centralised Six Sigma deployment versus a decentralised integrated Six Sigma programme. 


\subsubsection{Q uestionnaire}

Next, 102 questionnaires were e-mailed to a randomly-selected group of employees selected from the company's email list. To qualify as a potential respondent, the employee had to have been employed at management level in Lonmin at the conclusion of the original deployment phase of the Six Sigma programme, and had still to be in the employment of the organisation in 2010 (that is, after the restructuring and reorganisation programme conducted in 2008). The respondents were requested to complete the questionnaire and to return it by e-mail to the researcher. Of the 102 questionnaires sent out for completion, 54 were returned, representing eight per cent of the population. (The total number of employees at management level was 650.) With a confidence level of 95 per cent and a sample size of 54 , this yields a confidence interval of 12.78 per cent for a population size of 650 . This means that if 50 per cent of the sample selects an answer for a specific question, one can be 95 per cent confident that the entire population between 37.22 per cent (5012.78) and 62.78 per cent $(50+12.78)$ would have selected that same answer. The data was collated into an Excel spread sheet that was then analysed using the SPSS statistical analysis tool.

\subsubsection{Deployment archive}

The deployment data was stored within the portfolio management software (E-track) that was purchased at the onset of the deployment to manage project execution with the DMAIC toll gating process, and to form a knowledge base of all the activities associated with the deployment programme. This has provided a rich source of information about the deployment process and the strategy adopted in order to maximise the chances of success.

\subsubsection{Data analysis techniques}

The data obtained from part three of the quantitative questionnaire was subjected to statistical analysis, using the SPSS software package. Responses to the statements are captured in a two dimensional matrix, with the statements listed on the horizontal axis and the scores reflected on the questionnaire tabulated on the vertical axis. Respondents were asked to indicate their agreement with the statements using a 5-point Likert scale. Two statistical techniques were used: factor analysis and paired sample t-tests. Factor analysis was used to find the underlying subset of variables (called 'components' in this paper) from which the observed variables were generated. The set of 13 indicators and 40 success factors was subjected to factor analysis to identify any underlying components.

To answer the research question, 'What is the level of Six Sigma deployment in Lonmin PLC in 2010 compared with its initial deployment level in 2006?', paired sample t-tests were used to estimate the difference between the two population means for the 2006 deployment (before transformation in 2008) and the 2010 deployment (two years after the transformation). The respondents were asked to rate the 13 indicators and 40 success factors on a 5-point Likert scale for the state of the deployment in 2006 and the state of the deployment in 2010. Paired sample t-tests were conducted to establish if there was a significant difference between the sample means of the paired samples at the 95 per cent confidence interval.

\section{EMPIRICAL RESULTS}

This section is divided into three parts. The first part compares individual indicators (indicator 1 to indicator 13 ) between the two periods (2006 vs 2010). Paired sample t-tests were performed for this comparison. The second part is an exploratory analysis of the 13 indicators for each of the two periods. Further underlying components (or groups) amongst the 13 indicators were identified using factor analysis and then compared between the two periods. Lastly, the third part of this section reports the underlying components among the 40 success factors in each period using factor analysis.

\subsection{Paired sample t-test}

The questionnaire was constructed to produce a set of paired observations that contrasted the situation before and after the restructuring and re-organisation process, in order to 
understand the impact of the change on the factors identified as key to the success of a Six Sigma deployment. As 54 questionnaires were completed, the degrees of freedom (df) is $n$ 1 , or 53. The results, given in Table 1, show that the variables in 2006 have larger mean values than in 2010, and that the paired sample t-test indicates a significant difference between the two sets of means. There has been a shift in opinion regarding the success of the deployment in 2006 versus that in 2010, with the 2006 deployment being considered more successful. The possible reasons for this change in opinion will be explored in the concluding section below, and recommendations will be offered to address these issues.

Table 1: Means and standard deviation of indicators in 2006 and 2010

\begin{tabular}{|c|c|c|c|}
\hline & & Mean & Std. Deviation \\
\hline \multirow{2}{*}{ Pair 1} & Indicator 1 in 2006 & 4.28 & 0.730 \\
\hline & Indicator 1 in 2010 & 1.66 & 0.895 \\
\hline \multirow{2}{*}{ Pair 2} & Indicator 2 in 2006 & 4.08 & 0.778 \\
\hline & Indicator 2 in 2010 & 1.80 & 0.969 \\
\hline \multirow{2}{*}{ Pair 3} & Indicator 3 in 2006 & 4.24 & 0.657 \\
\hline & Indicator 3 in 2010 & 1.64 & 0.898 \\
\hline \multirow{2}{*}{ Pair 4} & Indicator 4 in 2006 & 4.36 & 0.598 \\
\hline & Indicator 4 in 2010 & 2.20 & 1.178 \\
\hline \multirow{2}{*}{ Pair 5} & Indicator 5 in 2006 & 4.62 & 0.567 \\
\hline & \begin{tabular}{|l|} 
Indicator 5 in 2010 \\
\end{tabular} & 1.78 & 1.036 \\
\hline \multirow{2}{*}{ Pair 6} & Indicator 6 in 2006 & 4.26 & 0.751 \\
\hline & Indicator 6 in 2010 & 1.64 & 1.005 \\
\hline \multirow{2}{*}{ Pair 7} & Indicator 7 in 2006 & 4.26 & 0.723 \\
\hline & Indicator 7 in 2010 & 1.38 & 0.830 \\
\hline \multirow{2}{*}{ Pair 8} & Indicator 8 in 2006 & 4.10 & 0.763 \\
\hline & Indicator 8 in 2010 & 1.86 & 1.069 \\
\hline \multirow{2}{*}{ Pair 9} & Indicator 9 in 2006 & 4.54 & 0.542 \\
\hline & Indicator 9 in 2010 & 2.40 & 1.325 \\
\hline \multirow{2}{*}{ Pair 10} & Indicator 10 in 2006 & 4.42 & 0.609 \\
\hline & Indicator 10 in 2010 & 1.58 & 0.906 \\
\hline \multirow{2}{*}{ Pair 11} & Indicator 11 in 2006 & 3.76 & 0.870 \\
\hline & Indicator 11 in 2010 & 2.68 & 1.220 \\
\hline \multirow{2}{*}{ Pair 12} & Indicator 12 in 2006 & 3.50 & 0.974 \\
\hline & Indicator 12 in 2010 & 2.46 & 1.110 \\
\hline \multirow{2}{*}{ Pair 13} & Indicator 13 in 2006 & 3.94 & 0.867 \\
\hline & Indicator 13 in 2010 & 1.90 & .995 \\
\hline
\end{tabular}

\subsection{Indicators of successful Six Sigma deployment in 2006 and 2010}

\subsubsection{Indicators of a successful deployment in 2006}

A reliability test performed on all 13 indicators resulted in a Cronbach's Alpha value of 0.328. This low Cronbach's Alpha value implies that all 13 indicators together do not represent a single construct for the indicators in 2006. In other words, underlying components may exist; and therefore a factor analysis was performed resulting in three components for the indicators of 2006 (see Table 2).

Table 2: Factor analysis for indicators in 2006

\begin{tabular}{|c|c|c|}
\hline \multicolumn{3}{|c|}{ Indicator Components (IC) in 2006 } \\
\hline IC 1 & IC 2 & IC 3 \\
\hline Motivation & Engagement & Empowerment \\
\hline Indicator 2 & Indicator 12 & Indicator 6 \\
Indicator 1 & Indicator 11 \\
Indicator 4 & Indicator 13 7 \\
Indicator 9 & Indicator 3 & Indicator 10 \\
\hline
\end{tabular}

Indicator Component No. 1 (Indicators 2, 1, 4, and 9) relates to questions about the deployment plan, participation and commitment of the senior executives, technical support from Master Black Belts and Black Belts, and a system to track Six Sigma projects. This can be described as the 'Motivating' component. 
Indicator Component No. 2 (Indicators 12, 11, 13, and 3) relates to questions about internal and external suppliers, a safe environment for employees, internal and external customers, and regular project reviews. This component can best be described sas 'Engagement'.

Indicator Component No. 3 (Indicators 6, 7, and 10) relates to Six Sigma training, communication, and an incentive programme. This can best be described as the 'Empowering' component.

Indicators 5 and 8 did not load on to any of the components identified during the factor analysis. Indicator 5 relates to the use of full-time Six Sigma Master and Black Belts within the deployment programme, and indicator 8 describes the use of a project selection methodology to identify projects for execution via the DMAIC process.

\subsubsection{Indicators of a successful deployment in $\mathbf{2 0 1 0}$}

As opposed to the analysis of the 2006 data, the Cronbach's Alpha value is 0.931 for the 13 items in the 2010 data. This high value implies that all 13 items represent a single construct that can be described as the 'Level of Six Sigma deployment in 2010'. Further factor analysis yielded three components (see Table 3) with Cronbach's Alpha values greater than 0.70 .

Table 3: Factor analysis for indicators in $\mathbf{2 0 1 0}$

\begin{tabular}{|c|c|c|}
\hline & \multicolumn{2}{|c|}{ Indicator Components (IC) in 2010 } \\
\hline IC 1 & IC 2 & IC 3 \\
\hline Systems & Competence & Empowerment \\
\hline Indicator 1 & Indicator 6 & Indicator 11 \\
Indicator 2 & Indicator 4 \\
Indicator 7 & Indicator 8 12 \\
Indicator 5 & Indicator 9 & \\
Indicator 10 & & \\
Indicator 3 & & \\
Indicator 13 & & \\
\hline
\end{tabular}

Indicator Component No. 1 (Indicators 1, 2, 7, 5, 10, 3, and 13) relates to questions about the deployment plan (1), participation and commitment of the senior executives (2), communication (7), full-time Master Black Belts and Black Belts (5), an incentive programme (10), regular Six Sigma projects reviews (3), and a six Sigma programme that focuses on the needs of the internal and external customers (13). This can be described as the 'Systems' component.

Indicator Component No. 2 (Indicators 6, 4, 8, and 9) relates to questions about a training programme for all employees (6), technical support from Six Sigma Master Black Belts and Black Belts (4), a Six Sigma project selection methodology (8), and a system to track Six Sigma projects (9). This component can best be described as 'Competence' .

Indicator Component No. 3 (Indicators 11 and 12) relates to a safe environment that allows employees to tell the truth (11), and a clear plan for dealing with internal and external suppliers (12). This can best be described as the 'Empowering' component.

\subsubsection{Comparing indicator components for 2006 and 2010}

From Table 4 one can observe that there has been a change in tone between the indicators identified in 2006 and 2010. This change can be described as being from personal heartfelt involvement and 'buy in' to a mechanistic performance-based culture. Common to both periods is the concept of empowerment. However, when reviewing the opinions provided by the respondents, it is observed that the shift in 2010 is away from personal empowerment. The focus in 2006 was to empower the workforce and the individual to be engaged in the deployment, and aggressively to drive Six Sigma performance and consequently organisation performance and rewards. 
Table 4: Indicator components in 2006 and 2010

\begin{tabular}{|c|c|c|}
\hline Indicator Component & 2006 & 2010 \\
\hline 1 & Motivation & Systems \\
\hline 2 & Engagement & Competence \\
\hline 3 & Empowerment & Empowerment \\
\hline
\end{tabular}

'Motivation' in 2006 was generated by the opportunity for participation in project definition, a clearly articulated and shared deployment plan, strong technical support from Six Sigma Black and Master Black belts, and a clearly defined tracking system that allowed employees to monitor their performance within the context of project and incentive performance. A road map describing the journey of transformation and the Six Sigma deployment allowed individuals to align their own vision and values with those of the organisation, creating a high level of personal and corporate motivation.

'Engagement' in 2006 relates to the regular contact with suppliers and customers, both internal and external to the organisation, a safe environment within which to challenge colloquial wisdom (essential for continuous improvement), and regular, inclusive project reviews that allowed all employees to engage with management in a constructive yet challenging dialogue around company performance.

This is less common in many organisations today where employees reaffirm management decisions and reflect poor performance as being acceptable or even exceptional and where the reality is that rewards are based on compliance and not performance and continuous improvement. The failure of some organisations since 2007 can be attributed to this phenomenon.

'Empowerment' in 2006 relates to the provision of training for employees, a rewarding incentive programme, and a strong communication system that provides forums for discussion, and that makes use of both formal and informal channels of communication. The growth of modern communication in the form of Facebook, Twitter, and blogging creates a new and unique opportunity in South Africa, where cell phone technology has saturated the corporate landscape.

The year 2010, however, has seen a fundamental restatement of the working environment, with indicators loading differently on the indicator components.

'Systems' in 2010 refers to the presence of a deployment plan, participation in the programme, communication, full-time resources, an incentive programme, project reviews, and customers. There has, however, been a significant shift in the individual views of the respondents, in that the programme was viewed as a mechanistic and systems-based approach that failed to capture the hearts or the imagination of the employees. This approach, when viewed in the light of the success of the 2006 focus on individual and team motivation, shows why the common view in 2010 was that Six Sigma had been sacrificed during the re-organisation and re-engineering initiatives that took place in 2008 during the global economic crisis.

'Competence' in 2010 refers to the provision of training, technical support, project selection, and tracking systems, and reaffirms the fundamental shift from employee motivation, engagement, and empowerment to a systems approach that is less personal and more mechanistic in nature.

The only common indicator between the two deployment periods is 'empowerment'; but again the shift in 2010 has been from training, communication, and incentives to a safe environment and interaction with suppliers. A review of the individual comments of the respondents shows a lack of trust in management support for the Six Sigma programme, and a clear sense that empowerment is seen as a 'lack of employee empowerment' rather than an environment that supports constructive engagement and challenging of the status quo. 
A shift has taken place in the hearts and minds of employees. In an industry that remains highly reliant on employee relationships, engagement, and motivation to be successful, a systematised approach should be considered risky. Systems are enablers of performance; but without the motivation, engagement, and empowerment of the workforce, a sustainable transformation to improved performance is unlikely to take place.

\subsection{Success factors of Six Sigma deployment in 2006 and 2010}

Factor analysis was performed on 40 success factors, and resulted in specific underlying factor groupings (also called 'components') for this study. Factor analysis was performed for both sets of success factors (for 2006 and 2010). The factor analysis results for both sets of success factors are shown in Tables 5 and 6 respectively. The components were given names based on the commonality of the success factors that were loaded on to the components. The success factor components have reduced from nine in 2006 to five in 2010, with only 'resources' being common to both. There has been a move from an empowering and engaging style of management and leadership to one that is focused on trying to create alignment and involvement of the stakeholders and employees by means of reviews.

Table 5: Factor analysis for success factors in $\mathbf{2 0 0 6}$

\begin{tabular}{|l|l|l|}
\hline \multicolumn{2}{|l|}{ Success factor components (SFC) in $\mathbf{2 0 0 6}$} \\
\hline SFC 1 & Resources & Factors $11,15,40,13,35,16,2,18,6$ \\
\hline SFC 2 & Communication & Factors $32,38,36,10,39,12,29$ \\
\hline SFC 3 & Selection & Factors $37,17,14,28,27,26$ \\
\hline SFC 4 & Feedback & Factors 5, 1, 34, 8, 30, 3 \\
\hline SFC 5 & Participation & Factors 9, 22, 20 \\
\hline SFC 6 & Commitment & Factors 4, 7, 33 \\
\hline SFC 7 & Planning & Factors 31, 21 \\
\hline SFC 8 & Support & Factors 19, 25, 23 \\
\hline SFC 9 & Tolerance & Factor 24 \\
\hline
\end{tabular}

Table 6: Factor analysis for success factors in $\mathbf{2 0 1 0}$

\begin{tabular}{|l|l|l|}
\hline \multicolumn{3}{|l|}{ Success factor components (SFC) in $\mathbf{2 0 1 0}$} \\
\hline SFC 1 & Stakeholders & Factors $32,7,38,30,34,29,33,37,4,36,22,39,8,28$ \\
\hline SFC 2 & Reviews & Factors $10,2,3,21,19,26$ \\
\hline SFC 3 & Resources & Factors $15,11,13,40,35,16,18,6,27$ \\
\hline SFC 4 & Management & Factors $23,20,24,9,5,31$ \\
\hline SFC 5 & Alignment & Factors $12,14,17,25,1$ \\
\hline
\end{tabular}

\section{CONCLUSION}

\subsection{Research results}

Three methodologies were used during the research project to establish a set of factors that could lead to the successful deployment of Six Sigma within the mining industry in South Africa. 'Success' could be described as delivering savings or revenues that flow through to the bottom line on a sustainable basis. Two distinct periods were studied: before and after the restructuring and reorganisation process that took place in Lonmin in 2008. The initial deployment was based on a decentralised 'centre of excellence' approach, with the Six Sigma team and infrastructure operating independently of the business and, in essence, contracting their services to the business. They had their own deployment plan, communication structure, and regular project reviews, and there was a significant commitment from the CEO and the executive team to the deployment. Extensive training was provided to all employees, and the company's top talent were encouraged to join the programme. Six Sigma resources were provided to support the programme, and the project selection process was vigorous. Potential projects were scoped and defined in conjunction with the business leaders. Technical support was provided to the programme by an external Six Sigma deployment specialist (CSI), and an appropriate number of Six Sigma Master Black 
Belts and Black Belts were trained and utilised on a full-time basis. To encourage sustainable deployment, the CEO committed to the on-going development of all six Sigma Master Black Belts and Black Belts, and a promise was made that all future executive and senior management posts would be filled from the Six Sigma Black Belt pool. Less clearly defined in the minds of the respondents and the archival material examined was a commitment to the external customer and external supplier. This should be considered a serious oversight, as the normal focus of Six Sigma deployments is generally on these two groupings. Following the restructuring and reorganisation process in 2008, there is little evidence of regular communication efforts: project reviews were discontinued; the incentive programme that had been a key component of the motivation and commitment exhibited by the Six Sigma resources was discontinued and incorporated into the organisation's balanced score card; the Six Sigma training programmes were discontinued; the Six Sigma projects were no longer tracked; and the Black Belts and Master Black Belts were reincorporated into the business. Some of these human resources were retrenched or forced to return to the business in lesser roles with lower pay than they had been receiving in the Six Sigma programme.

Compared with 2010, the indicators from 2006 point to a more successful deployment of Six Sigma in Lonmin. The 13 indicators from 2006 are loaded on to three indicator components, namely Motivation, Engagement, and Empowerment. Moreover, in the analysis of the success factors, the factor components from 2006 did not re-occur in 2010 - apart from resources. When considering the 13 indicators shown in Figure 7, it can be seen that all the mean values during 2006 are higher than those during 2010. This result indicates that Lonmin deployed Six Sigma more successfully in 2006 than it did in 2010.

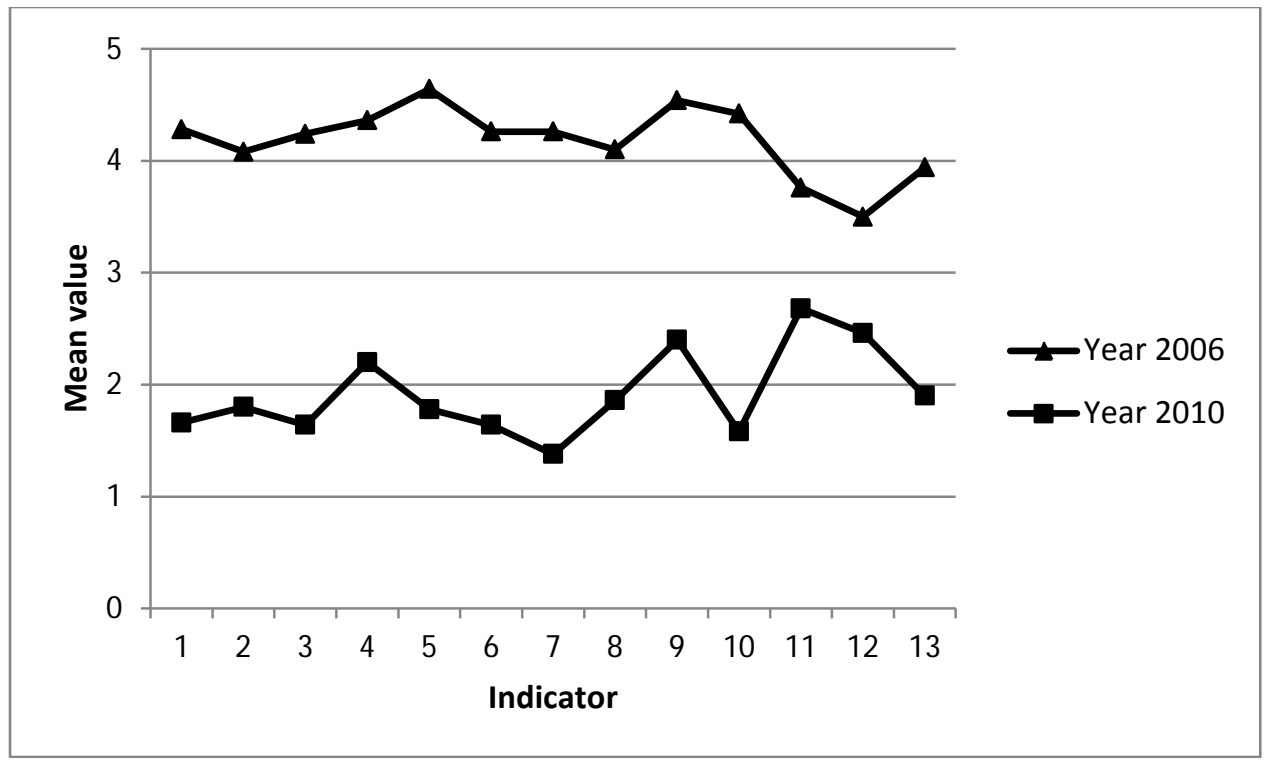

Figure 7: Comparison of indicators in year 2006 and year 2010

It is therefore recommended that the success factor components from 2006 should be taken into account in future Six Sigma deployment initiatives. In greater detail, these factor components can be described as follows:

1. Resources must be provided to the deployment programme, and these must include fulltime Six Sigma resources, incentive programmes, and the Six Sigma tools required to analyse data and track project progress and success. Training opportunities and the opportunity to be incorporated back into the business at a more senior level than that in which the employee was engaged in the Six Sigma programme will also confirm the level of commitment shown by the senior and executive management teams. 
2. Communication must take place via a series of initiatives such as newsletters, personal interaction, quarterly performance reviews, and individual coaching and mentoring. Communication needs to address the full spectrum of opportunities, with both formal and informal approaches being encouraged. The availability of accurate and real-time information is essential to the success of communication. In the absence of reliable information employees create their own reality, and during times of significant and sustained change this is often negative in character. Openness and transparency are essential to the success of the communication process.

3. Selection of high value projects and incorporation of the company's top talent into the programme is essential to ensure sustainable deployment. Projects that lead to quick wins will create an environment of success. It is well-documented that success breeds confidence, and confidence results in success; so the development of high-performing teams requires quick wins to spark sustainable performance. Selecting the best employees, and providing them with 'low hanging fruit' projects, is the best way to achieve this. Selection is therefore a key ingredient in the success of a Six Sigma deployment.

4. Feedback on the company's performance in respect of Six Sigma savings and revenue projects, the impact on the bottom line, and the potential rewards that the incentives programmes will be paying out, needs to be undertaken on a regular basis. Systems that provide real-time feedback would be beneficial, and would help to empower the teams to be successful.

5. The participation of all employees and management in the programme will ensure a consistency of purpose and goal alignment. Participation empowers employees and creates a platform from where their voices can be heard. This is a key factor in creating an empowered and motivating environment, and key to the success of any business initiative.

6. Commitment by senior management and the executive is essential to the success of deployment. They create the vision and, by walking the talk, they indicate their commitment to the initiative. By personally attending all Six Sigma functions, training programmes, and certification ceremonies, and by achieving a level of Six Sigma certification themselves, they are clearly signalling that the initiative is sustainable and essential to the success of the organisation.

7. Planning: Creating the deployment, communication, and internal and external customer plans is important. Involving the appropriate level of employees and management will ensure that the planning process is inclusive and holistic, and will assist in the process of gaining acceptance and commitment to the plan. This is also the ideal time to create the set of goals, targets, and metrics that will enable tracking of progress and performance against the plan, and will enable project managers the opportunity to communicate the need for extra resources should projects be in trouble. An escalation policy is required to ensure that the appropriate level within the organisation is notified timeously of any deviation, to enable support.

8. Support can be viewed as a proxy for the factors discussed in this section of the report. Access to resources, training, incentive programmes, and redeployment to the business in more senior levels than the incumbent is currently in are all tacit evidence of a supportive environment. By the same token, regular and clear communication, participation, planning, and tolerance are also evidence of a supportive and inclusive operating system. Initiatives that have the full support of management and the organisational infrastructure have an above-average chance of success.

9. Tolerance: The success of any major change management or transformation process is dependent on the level of tolerance that management shows to the opinions, attitudes, 
and criticisms of its employees. By allowing employees the space and opportunity to be critical, to challenge management wisdom, and to tackle organisational 'holy cows', an environment of tolerance and creative tension is created that brings out the best.

\subsection{Contributions to theory and practice}

The Six Sigma methodology has found great support in Northern and Central America, and to a lesser extent in Europe and Asia. In South Africa, however, there has been very little penetration into the corporate environment: the ISO and local standards are still favoured for quality and continuous improvement management. The Six Sigma continuous improvement methodology could therefore represent an opportunity for the South African mining industry, which is experiencing a period of declining productivity, profits, and safety standards. The methodology has not been implemented at any significant level in the South African mining industry to enable the quantification of its potential impact on the industry. Lonmin, as the pioneer practitioner of Six Sigma methodology in the South African mining industry, is used as a case study to identify a set of indicators that can indicate the level of Six Sigma deployment; a set of success factors is also identified that ensures successful Six Sigma deployment.

This study contributes to the field of Six Sigma in three ways. First, it applies statistical techniques to compare the indicators and success factors for two different years. This allows policy makers or managers to observe the longitudinal shift of focus in these variables, and thus identify the possible reasons for poorer (or better) deployment of Six Sigma over a period of time. Second, these variables are identifiable within the social sciences. The choices of these variables are in line with the argument that human elements are essential for Six Sigma deployment [18], and that Six Sigma programmes have been abandoned because inadequate attention is paid to human issues [19]. Third, this is one of the few studies that report and discuss Six Sigma deployment in countries with an emerging economy. Researchers have pointed out that little data is published about the use of Six Sigma in a developing country, and that there is a need to expand knowledge on this subject $[20,21]$. Thus this study contributes to Six Sigma literature in countries with emerging economies, especially those in the mining industry that have not yet experienced Six Sigma implementation, so that they can become aware of the success factors behind Six Sigma deployment.

\subsection{Managerial recommendations}

From this study the magnitude of deploying Six Sigma within an organisation - and more specifically within the mining industry in South Africa - is explored. There is the need to tread cautiously, as many pitfalls await an organisation if it ignores a number of key requirements and fails to take into account a number of identified key success factors. The deployment can be undertaken as a stand-alone initiative, or as an integrated management methodology in conjunction with a change management process and a strategy formulation initiative. Either methodology will work, but the identified key success factors need to form the cornerstone of the deployment. Focusing on these factors will increase the potential for success significantly. A model that integrates the Six Sigma methodology with Kotter's change management process and the Kaplan and Norton strategy maps has been formulated in this study, and this can be used to manage an integrated deployment initiative. This is particularly necessary in the light of significant pressure on the South African mining industry from employment equity legislation and the recently-signed Environment Policy Circular 42/10, to achieve organisational transformation. The circular, for example, commits the DME, NUM, Chamber of Mines, SAMDA, Solidarity, and UASA to a series of programmes including investment, infrastructure, innovation, sustainable development, beneficiation, regulatory framework, human resources development, employment equity, mine community development, housing and living conditions, procurement, ownership and funding, and monitoring and evaluation [22].

Based on these many different and complex requirements - and the tight deadline of 2014 it is recommended that a COE centralised approach be followed, should a Six Sigma deployment be contemplated. The programme can be clearly defined, resources can be 
allocated, and projects can easily be tracked and managed with matching benefits and rewards. The Six Sigma skill set and training can be rapidly developed if the top talent of the organisation are enrolled in the programme. The deployment can also be shut down at short notice, should little value accrue from the initiative, without catastrophic impact on the rest of the organisation. In the current climate, with mining companies struggling for survival and growth, the integrated approach is extremely risky. In this instance, the recommended strategy is to be a 'tortoise' rather than a 'hare'.

\subsection{Limitations of the study}

The study focuses on Lonmin PLC, which is one company operating within the South African mining environment. Consequently the results cannot be generalised to all companies operating in the mining industry. As Six Sigma has not been deployed in many South African mining companies, a comparative study is extremely difficult. The learnings gained from the study can, however, be compared with those gained from the literature review, and access to Lonmin's deployment database could reveal insights that would assist companies that are about to embark on their own deployments. The semi-structured interviews were conducted with those employees who were intimately involved in the Six Sigma deployment process, and the quantitative interviews were conducted with a random sample of Lonmin's total employee complement. Due to the significant turnover of employees during the transformation process that started in 2004, the sample may be biased by the fact that those employees who remained with the company supported the deployment and transformation, and so may have responded to the interviews more positively than those who chose to leave the company.

\subsection{Future research recommendations}

This research suggests a number of directions for future research. First, it explores the indicators and factors for successful Six Sigma deployment using factor analysis. The causal relationships between the factors and the indicators could be further analysed in future studies. From such a study, one would be able to identify those success factors that have critical impact on the success of Six Sigma deployment. Organisations often use this critical success factor approach as a framework for strategic planning [39]. Second, this research was carried out in an emerging economy. Similar studies could be done in other countries with emerging economies to benchmark the results of this research. Third, there are other continuous improvement strategies - such as Total Quality Management, Lean, Lean Six Sigma, and others [40] - and they could be included in future studies. Consequently, additional studies related to these different strategies in various combinations could be used to explore further the indicators and factors of successful improvement.

\section{REFERENCES}

[1] Nattrass, N. 1995. The crisis in South African gold mining, World Development, 23(5), pp 857868.

[2] Baxter, R. 2008. The global economic crisis and its impact on South Africa and the country's mining industry. Conference papers of the South African Reserve Bank Conference series on Challenges for Monetary Policy-makers in Emerging Markets, South Africa.

[3] Lonmin website. South African Mining Charter, Lonmin. Retrieved from: http://www. Ionmin. com/ assets/ pdf/ south\%20african\%20mining\%20charter. pdf

[4] DTI website. Broad-based socio-economic empowerment charter for the South African mining industry. Department of Trade and Industry. Retrieved from http://bee.thedti.gov.za/docs/ Mining. pdf

[5] South African Reserve Bank website. 2011. Quarterly Bulletin June 2008. Retrieved from http:/ / www. resbank. co. za/ Lists/ News\%20and\%20Publications/ Attachments/ 4072/ Full\%20Quarter ly\%20Bulletin.pdf

[6] Department of Mineral Resources. Beneficiation economics. Retrieved from http:/ / www.dmr.gov.za/ beneficiation-economics. html

[7] Madua, S. 2010. Stakeholders' declaration on strategy for the sustainable growth and meaningful transformation of South Africa's mining industry. RSA: Chamber of Mines of South Africa.

[8] Hodge, D. 2009. Growth, employment and unemployment in South Africa, South African J ournal of Economics, 77(4), pp 488-504. 
[9] Barney, M. 2002. Motorola's second generation, Six Sigma Forum Magazine, 1(3), pp 13-16.

[10] Desai, T.N. \& Shrivastava, R.L. 2010. Six Sigma - A breakthrough improvement strategy for business improvement - An overview, International Journal of Research in Commerce and Management, 1(5), pp 88-99.

[11] Truscott, W.T. 2003. Six Sigma: Continual improvement for businesses, Butterworth-Heinemann.

[12] Lowe, J. 1998. J ack Welch speaks, Wiley.

[13] Kotter, J.P. 1996. Leading change, Harvard Business School Press.

[14] Kaplan, R.S. \& Norton, D.P. 2004. Strategy maps: Converting intangible assets into tangible outcomes, Harvard Business School Press.

[15] Kaplan, R.S. \& Norton, D.P. 2001. The strategy focused organization, Harvard Business School Press.

[16] Gitlow, H.S. \& Levine, D.M. 2005. Six Sigma for green belts and champions - Foundations, DMAIC, Tools, Cases and Certification, Prentice Hall.

[17] Kaplan, R.S. \& Norton, D.P. 1996. The balanced scorecard, Harvard Business School Press.

[18] Anthony, J. \& Banuelas, R. 2002. Key ingredients for the effective implementation of Six Sigma program, Measuring Business Excellence, 6(4), pp 20-27.

[19] Pande, P.S., Neuman, R.P. \& Cavanagh, R.R. 2000. The Six Sigma way: How GE, Motorola and other top companies are honing their performance, McGraw-Hill Professional.

[20] Henderson, K.M. \& Evans, J.R., 2000. Successful implementation of Six Sigma: Benchmarking General Electric Company, Benchmarking: An International J ournal, 7(4), pp 260-281.

[21] Eckes, G. 2000. The Six Sigma revolution, J ohn Wiley \& Sons.

[22] Coronado, R.B. \& Anthony, J . 2002. Critical success factors for the successful implementation of Six Sigma projects in organisations, The TQM Magazine, 14(2), pp 92-99.

[23] Breyfogle, F.W., Cupello, J.M. \& Meadows, B. 2001. Managing Six Sigma: A practical guide to understanding, assessing and implementing the strategy that yields bottom-line success, Wiley.

[24] Harry, M. \& Schroeder, R. 2000. Six Sigma: The breakthrough management strategy revolutionizing the world's top companies, Currency.

[25] Smith, D., Blakeslee, J. \& Koonce, R. 2003. Strategic Six Sigma: Best practices from the executive suite, Wiley.

[26] Snee, R.D. \& Hoerl, R.W. 2003. Leading Six Sigma, Prentice-Hall.

[27] Kwak, Y.H. \& Anbari, F.T. 2006. Benefits, obstacles, and future of Six Sigma approach, Technovatio, 26, pp 708-715.

[28] Johnson, A. \& Swisher, B. 2003. How Six Sigma improves R\&D, Research Technology Management, 46(2), pp 12-15.

[29] Starbird, D. 2002. Business excellence: Six Sigma as a management system, ASQ's $56^{\text {th }}$ Annual Quality Congress Proceedings, pp 47-55.

[30] Ho, Y.C., Chang, O.C. \& Wang, W.B. 2008. An empirical study of key success factors for Six Sigma Green Belts projects at an Asian MRO company, Air Transport Management, 14, pp. 263269.

[31] Cornel, N., García, J., Noriega, S. \& Valdivieso, R. 2009. Critical success factors for Six Sigma implementation. Proceedings of the 14th annual International Conference on Industrial Engineering: Theory, Applications and Practice. Anaheim, California.

[32] Brun, A. 2011. Critical success factors of Six Sigma implementations in Italian companies, International J ournal of Production Economics, 131, pp 158-164.

[33] Sambhe, R.U. \& Dalu, R.S. 2011. Evaluation of Six Sigma implementation in medium scale Indian automotive enterprises, International J ournal of Engineering Science and Technology, 3(3), pp 1790-1796.

[34] Antony, J. 2006. Six Sigma for service processes, Business Process Management J ournal, 12(2), pp 234-248.

[35] Chakravorty, S.S. 2009. Six Sigma programs: An implementation model, International J ournal of Production Economics, 119(1), pp 1-16.

[36] Miguel, P.A.C. \& Andrietta, J.M. 2010. Outcomes from a descriptive survey of Six Sigma management practices in Brazil, International J ournal of Lean Six Sigma, 1(4), pp 358-377.

[37] Antony, J. \& Desai, D.A. 2009. Assessing the status of Six Sigma implementation in the Indian industry: Results from an exploratory empirical study, Management Research News, 32(5), pp 413-423.

[38] Reid, A. 2010. The Mining Charter and the stakeholders' declaration. Quo vadis? Retrieved from http:/ / www. polity. org.za/ article/ the-mining-charter-and-the-stakeholders-declaration-quovadis-2010-07-20.

[39] Bullen, C.V. 1995. Re-examining productivity critical success factors, Information System Management, 12(3), pp 13-18.

[40] Goetsch, D. \& Davis, S. 2013. Quality management for organizational excellence: Introduction to total quality, $7^{\text {th }}$ edition, Pearson. 
Appendix 1. Description of Success Factors (SF) used in the questionnaire.

\begin{tabular}{|c|c|}
\hline SF & Description \\
\hline 1 & Understanding the requirements of internal and external customers \\
\hline 2 & $\begin{array}{l}\text { Master Black Belts and Black Belts meet on a weekly basis to analyse progress on Six Sigma } \\
\text { projects }\end{array}$ \\
\hline 3 & Financial reward for successful Six Sigma projects \\
\hline 4 & Visible commitment from the CEO for the Six Sigma deployment \\
\hline 5 & Having regular feedback on the state of the Six Sigma deployment \\
\hline 6 & Sufficient Black Belt and Master Black Belts to provide support to all six sigma projects \\
\hline 7 & A recognition program that rewards Six Sigma successes \\
\hline 8 & Monthly Six Sigma project reviews with the departmental operational teams \\
\hline 9 & Employees, Supervisors and Managers are all involved in Six Sigma projects \\
\hline 10 & Quarterly feedback to the Board regarding Six Sigma projects performance \\
\hline 11 & $\begin{array}{l}\text { A Six Sigma training program is in place that ensures that all employees are appropriately } \\
\text { trained for their level within the organization }\end{array}$ \\
\hline 12 & An integrated ERP package that provides suitable information to support Six Sigma Projects \\
\hline 13 & Master Black Belts and Black Belts act as teachers, mentors and coaches \\
\hline 14 & A clear set of business metrics which enables the selection of high value Six Sigma projects \\
\hline 15 & Master Black belts and Black belts are always available to assist with Six Sigma projects \\
\hline 16 & A software program that manages six sigma projects using the DMAIC stage gate approach \\
\hline 17 & Projects are linked to the organizational goals and objectives \\
\hline 18 & A certification process is in place that certifies Six Sigma belts \\
\hline 19 & An external trainer and facilitator are used for Six Sigma training \\
\hline 20 & A Six Sigma champion who is a member of the organizational executive committee \\
\hline 21 & $\begin{array}{l}\text { The deployment plan includes training, required infrastructure, communication and reward } \\
\text { strategies }\end{array}$ \\
\hline 22 & $\begin{array}{l}\text { Management have a hands on approach and are involved in weekly and monthly Six Sigma } \\
\text { reviews }\end{array}$ \\
\hline 23 & Six sigma reports are an essential part of on-going communication \\
\hline 24 & Mistakes on six sigma projects are considered a part of the learning culture \\
\hline 25 & $\begin{array}{l}\text { An open and safe environment that sees defects as improvement opportunities has been } \\
\text { cultivated }\end{array}$ \\
\hline 26 & An effective communication plan regarding progress on the Six Sigma deployment is in place \\
\hline 27 & All employees are trained in the DMAIC process \\
\hline 28 & All six sigma projects begin with the determination of the requirements of the customer \\
\hline
\end{tabular}




\begin{tabular}{|c|c|}
\hline SF & Description \\
\hline 29 & Reported Six Sigma project results include failures and success stories \\
\hline 30 & Suppliers are encouraged to have their own Six Sigma programs in place \\
\hline 31 & Schedule, costs and revenue generation are the key deliverables of every Six Sigma project \\
\hline 32 & $\begin{array}{l}\text { A communication program describing what should be communicated by whom and how often } \\
\text { regarding the Six Sigma deployment is in place }\end{array}$ \\
\hline 33 & Six sigma projects are linked to customers core processes and competitiveness \\
\hline 34 & Suppliers share in the successes of Lonmin"s six sigma deployment \\
\hline 35 & $\begin{array}{l}\text { All Six Sigma projects are resourced with Black Belts and Master Black belts who support the } \\
\text { project till it is completed }\end{array}$ \\
\hline 36 & Strategic alliances are developed with Six Sigma suppliers \\
\hline 37 & $\begin{array}{l}\text { Six Sigma project objectives include the quality requirements of the internal and external } \\
\text { customers }\end{array}$ \\
\hline 38 & The Six Sigma deployment plan has been made available to all employees \\
\hline 39 & Progress against the Six Sigma deployment plan is tracked on a monthly basis \\
\hline 40 & Master Black Belts and Black Belts are always available to provide support on projects \\
\hline
\end{tabular}

